\title{
Phylogenetic and Pathogenic Analyses Show That the Causal Agent of Apple Ring Rot in China Is Botryosphaeria dothidea
}

W. Tang and Z. Ding, Graduate Research Assistants, Department of Plant Pathology, China Agricultural University, Beijing, 100193, P. R. China; Z. Q. Zhou, Zhengzhou Fruit Research Institute, Chinese Academy of Agricultural Sciences, Zhengzhou, 450009 P. R. China; Y. Z. Wang, Yan Tai Agricultural Science and Technology Institute, Yan Tai, 265500, Shandong, China; and L. Y. Guo, Department of Plant Pathology, China Agricultural University, Beijing, 100193, P. R. China

\begin{abstract}
Tang, W., Ding, Z., Zhou, Z. Q., Wang, Y. Z., and Guo, L. Y. 2012. Phylogenetic and pathogenic analyses show that the causal agent of apple ring rot in China is Botryosphaeria dothidea. Plant Dis. 96:486-496.

Apple ring rot and Botryosphaeria canker are severe diseases affecting apple production in China, but there is confusion regarding which pathogens cause these diseases and their similarity to other diseases, such as white rot of apple, and ring rot and Botryosphaeria canker of pear. In this study, the pathogen of apple ring rot in China was compared with the pathogen of apple ring rot in Japan and Korea, the pathogen of Botryosphaeria canker of apple and pear in China, the pathogen of pear ring rot in China, and the pathogen of white rot of apple in the United States. Comparisons were based on morphology, pathogenicity on branches and fruit, and sequences of rDNA in the internal transcribed spacer region and of the $\beta$-tubulin and actin genes. Results showed that the causal agent of apple ring rot and Botryos-

phaeria canker of apple in China was Botryosphaeria dothidea, which has also been reported to be the pathogen of apple ring rot in Korea and Japan. Pathogenicity tests showed that B. dothidea infection on apple and pear branches may induce wart or canker symptoms depending on the conditions. These results are consistent with the hypothesis that the same pathogen causes the wart symptom of apple ring rot and the Botryosphaeria canker symptom on apple branches in China. The results also suggest that apple ring rot and white rot are the same disease and are caused by $B$. dothidea. Finally, $B$. dothidea isolates from pear and other fruit or forest trees may serve as inoculum for apple ring rot.
\end{abstract}

Ring rot is one of the most important diseases of apple in China. It is widely distributed in most apple growing areas in the country but is most severe in eastern China (Liaoning, Shandong, Henan, and Hebei provinces), where summer temperatures and rainfall are high (13). The earliest record of a severe loss caused by this disease in China was in Chengdu of Sichuan Province in 1942, when the disease caused approximately $20 \%$ fruit loss of Yuxia (Mapi) apples before harvest and another $79 \%$ loss in storage (35). Since the 1980s, the importance of apple ring rot in eastern China has increased with the widespread planting of the cultivar Fuji. With the increase in disease frequency and severity, apple growers in China have increasingly adapted the bagging of fruit (a practice of bagging each fruit individually on the tree right after fruit set to protect it from all kinds of damage) as a control method (unpublished observation).

On fruit, apple ring rot causes slightly sunken lesions with alternating tan and brown rings (Fig. 1A). Infected branches or trunks of young trees have warts that develop around lenticels (Fig. 1B). These warts crack as the infection progresses, and part of the periderm around the wart peels off (Fig. 1C and D). After several years of infection, rough skin with scaled periderm develops on older branches or on the trunk (Fig. 1E).

Apple ring rot also occurs in other countries in East Asia, such as Japan and South Korea $(17,21)$. The causal agent of "wart-bark symptoms" on apple was first reported in Japan as Physalospora

Corresponding author: L. Y. Guo,

E-mail:ppguo@cau.edu.cn and ppguoly@126.com

* The $e$-Xtra logo stands for "electronic extra" and indicates that a supplemental figure is included in the online edition.

Accepted for publication 26 October 2011.

http://dx.doi.org/10.1094/PDIS-08-11-0635

(C) 2012 The American Phytopathological Society piricola Nose, a taxon whose name was subsequently revised to Botryosphaeria berengeriana f. sp. piricola Koganezawa \& Sakuma. However, both $B$. berengeriana and B. berengeriana f. sp. piricola were identified as the causal agent of ring rot on fruit (18). In the Chinese literature, the causal agent of apple ring rot is currently listed as Botryosphaeria berengeriana f. sp. piricola, and its anamorph is referred to as Dothiorella following the Japanese literature of the 1980s $(2,13,18)$. Detailed studies on the identification of the pathogen of apple ring rot in China have not been previously reported.

The fruit rot symptoms of apple ring rot are very similar to those of white rot caused by Botryosphaeria dothidea (Moug. ex Fr.) Ces. \& De Not., which is a common disease in many apple growing areas around the world (16). The pathogen, B. dothidea, causes cankers characterized by the collapse of cortical cells and discolored areas on the bark, but has not been shown to cause the wartbark symptom, which is seldom observed in the United States. Because the name $B$. berengeriana $\mathrm{f}$. sp. piricola is rarely used outside of Asia and the wart symptoms caused by this pathogen on branches are different from the commonly observed symptoms of white rot on apple branches, B. berengeriana $\mathrm{f}$. sp. piricola is listed as a quarantine pest by the European Union (3). A recent study of Botryosphaeria spp. from deciduous fruits in Japan based on morphology of conidia and the nucleotide sequences of the rDNA internal transcribed spacer (ITS) region showed that the Botryosphaeria isolates associated with the wart-bark disease of apple in Japan appear to be similar to $B$. dothidea isolates that cause white rot in the United States (21). However, a pathogenicity test of these isolates was not included in the study and the quarantine status has remained.

Another disease that can cause branch cankers (Fig. 1F and G), dieback of twigs (Fig. 1H), and fruit rot in apple orchards in China is Botryosphaeria canker. The causal agent of this disease is referred to as Botryosphaeria ribis or B. dothidea $(1,2,7)$. Because the symptoms of apple ring rot and Botryosphaeria canker on branches and trunks are quite different (the former causes warts whereas the latter causes cankers and twig dieback), these have 
been regarded as different diseases in China. However, the fruit symptoms caused by these two diseases are indistinguishable (7). Moreover, ring rot and Botryosphaeria canker also occur on pears in China.

Botryosphaeria spp. have wide host ranges, and in addition to causing disease on apple, they also cause diseases of forest trees. For example, Botryosphaeria canker of poplar is a common disease in northern China where poplar is widely planted along roads. The pathogen of Botryosphaeria canker on poplar in China was regarded as $B$. ribis or $B$. dothidea depending on the reference, while some researchers considered the two synonymous (8). Whether pathogens that cause pear ring rot or related diseases on poplar and other deciduous trees can cause apple ring rot is not known.

The inconsistency in the Chinese literature of the name of the pathogen causing Botryosphaeria disease on apples is due not only to the lack of detailed study but also to the confusion regarding the overall taxonomy of the species in the genus Botryosphaeria $(4,30)$. Although teleomorph names are preferred, the anamorph features, in most species, are the only available characters for species identification. The overlapping morphological characteristics among the different species make it difficult to distinguish Botryosphaeria spp. from one another. Recent studies using both morphological characteristics and sequence data (rDNA ITS, SSU, EF1- $\alpha$, actin, and $\beta$-tubulin) and ISSR profiles of the ITS rDNA region have contributed significantly to the taxonomy of Botryosphaeria $(10,23,27-30,36-38)$. B. ribis is now distinct from $B$. dothidea, and its anamorph is accepted as Neofusicoccum ribis (27). Fusicoccum aesculi is considered the anamorph of $B$. dothidea (27), and Dothiorella with 1-septate brown conidia has been shown to be phylogenetically different from $B$. dothidea (23).

Understanding which species cause ring rot and Botryosphaeria canker and determining their potential inoculum sources are essential for developing effective control strategies. Furthermore, the correct identification of the pathogen is very important in the international trade of fruit products. Therefore, the objectives of this study were (i) to identify the pathogen of apple ring rot in China, (ii) to compare the pathogen of apple ring rot in China with that of pear ring rot and that of Botryosphaeria canker of apple and pear, (iii) to test the hypothesis that the wart-bark symptom of apple ring rot and Botryosphaeria canker on apple branches in China are caused by the same pathogen, and (iv) to determine whether Botryosphaeria spp. from other deciduous trees can serve as inoculum sources of apple ring rot. We accomplished these objectives by comparison of morphology, pathogenicity, and the DNA sequences of three genes.

\section{Materials and Methods}

Isolates used and morphological observation. Seventy-one isolates were used in this study (Table 1), and 57 of these were collected from major apple producing areas in China (Shandong, Liaoning, Henan, Beijing, Shanxi, Shaanxi, and Yunnan provinces). Of these 57 isolates, 43 were from either warts on apple branches or diseased tissue on apple fruit showing ring rot symptoms; eight were from cankers on apple branches; and six were from warts or cankers on pear twigs and fruit. The other 14 were reference isolates, including one isolate of $B$. berengeriana $\mathrm{f}$. $\mathrm{sp}$. piricola from Japan, two isolates of $B$. dothidea from apple ring rot in South Korea, five isolates of $B$. dothidea from apple white rot in the United States, isolates of $B$. dothidea (CBS115476) and $N$. ribis (CBS118822) from the Central Bureauvoor Schimmelcultures (CBS), and four isolates of $B$. dothidea from the China Forestry Culture Collection Center. The isolates were obtained from a single conidium or were purified through hyphal tipping. All the isolates were examined for colony morphology and used in the phylogenetic analysis of the ITS sequence. Representative isolates were then selected for use in the remaining studies. Isolates were grown and maintained on potato dextrose agar (PDA) at $25^{\circ} \mathrm{C}$ in the dark. The cultural characteristics of the isolates were determined on $2 \%$ PDA after 7 days at $25^{\circ} \mathrm{C}$. Isolates were cultured on $2 \%$ malt extract agar (MEA) with $12 \mathrm{~h}$ of an intermittent cycle of near UV light to induce sporulation. Mature pycnidia of each isolate were collected from MEA and crushed in sterile-distilled water in a micro-centrifuge tube. The conidial suspension was then filtered through three layers of lens paper to remove mycelia and pycnidial debris. Conidial morphology was observed with a light microscope at $\times 400$ magnification, and the length and width of 50 conidia per isolate were determined.

DNA extraction, sequencing, and phylogenetic analysis. Genomic DNA from all 71 isolates was extracted from fungal mycelia using the FastDNA kit and the FastPrep FP-24 instrument (MP Biomedicals Inc., Irvine, CA) according to the manufacturer's instructions. The ITS region of rDNA was amplified with the primers ITS 1 (5'-TCCGTAGGTGAACCTGCGG-3') and ITS4 (5'TCCTCCGCTTATTGATATGC-3') (34). The partial $\beta$-tubulin gene was amplified with the primers Bt2a (5'-GGTAAC CAAATCGGTGCTGCTTTC- $\left.3^{\prime}\right)$ and Bt2b (5'-ACCCTCAGT GTAGTGACCCTTGGC-3') (12). The partial sequence of the actin gene was amplified with the primers ActF (5'-CGTCTT CCGTAAGTCTCCCC- $\left.3^{\prime}\right)$ and ActR (5'-TACGAGTCCTTC TGGCCCAT- $3^{\prime}$ ), which were designed in this study based on the sequence of actin genes of B. dothidea in GenBank (AY972117 and AY972118). The PCR mixture contained $1.0 \mu \mathrm{l}$ of $10 \mathrm{mM}$ forward primer, $1.0 \mu \mathrm{l}$ of $10 \mathrm{mM}$ reverse primer, $38.5 \mu \mathrm{l}$ of $\mathrm{ddH}_{2} \mathrm{O}$, $1 \mathrm{U}$ Pfu DNA polymerase, $5 \mu \mathrm{l}$ of $10 \times$ polymerase reaction buffer, $0.2 \mathrm{mM}$ each dNTP, and 10 to $50 \mathrm{ng}$ of DNA template.

The PCR conditions used for ITS and $\beta$-tubulin primers were: an initial denaturation for $3 \mathrm{~min}$ at $94^{\circ} \mathrm{C}$; followed by 35 cycles of 30 $\mathrm{s}$ at $94^{\circ} \mathrm{C}, 30 \mathrm{~s}$ at $55^{\circ} \mathrm{C}$, and $90 \mathrm{~s}$ at $72^{\circ} \mathrm{C}$; and a final extension of $10 \mathrm{~min}$ at $72^{\circ} \mathrm{C}$. The PCR conditions used for actin primers were: an initial denaturation for $3 \mathrm{~min}$ at $94^{\circ} \mathrm{C}$; followed by 35 cycles of $30 \mathrm{~s}$ at $94^{\circ} \mathrm{C}, 30 \mathrm{~s}$ at $61^{\circ} \mathrm{C}$, and $30 \mathrm{~s}$ at $72^{\circ} \mathrm{C}$; and a final extension of $10 \mathrm{~min}$ at $72^{\circ} \mathrm{C}$. PCR products were purified and sequenced by Shenggong Biotech Co., Ltd. (Shanghai, P.R. China). All sequences were edited with Bio-Edit (14) with manual adjustment; ambiguous regions on both sides were excluded from the analyses. Phylogenetic analyses were carried out based on the ITS sequences, the $\beta$-tubulin sequences, the actin sequences, and combined data set of the above three regions. The minimum evolution (ME) analyses were performed using the Tajima-Nei test in MEGA 4.0 (33). Gaps were treated as a fifth character weight, and all characters were unordered of equal weight (25). The sequence of Glomerella cingulata (Stoneman) Spauld. \& H. Schrenk was used as the outgroup. Bootstrap values were estimated by 1,000 replications of random sequence and trees were viewed by MEGA 4.0.

Pathogenicity testing. Based on the morphological and molecular data, selected isolates were tested for their pathogenicity on

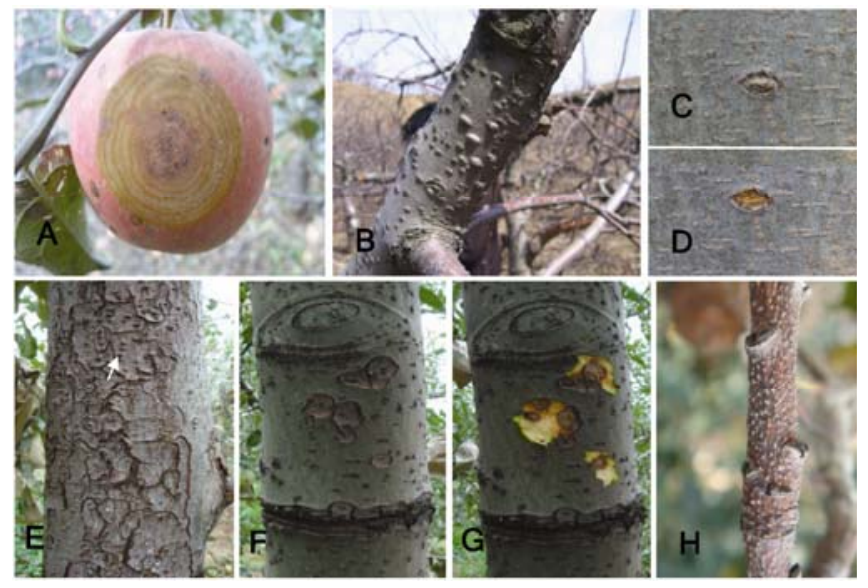

Fig. 1. Disease symptoms of apple ring rot and Botryosphaeria canker on apple trees in orchards. A, Fruit ring rot. B, Warts on a branch. C and D, Periderm around the wart peels off. E, Rough skin with scaled periderm with wart (indicated by arrow) on trunk. F and $\mathbf{G}$, Sunken cankers typical of Botryosphaeria infections in western China; during hot dry weather cankers often expand and coalesce, girdling the branches. H, Twig dieback. 


\begin{tabular}{|c|c|c|c|c|c|c|c|c|c|c|c|}
\hline \multirow[b]{3}{*}{ Isolates $^{\mathbf{v}}$} & \multirow[b]{3}{*}{ Species } & \multirow{2}{*}{\multicolumn{3}{|c|}{ Origin }} & \multicolumn{4}{|c|}{ Pathogenicity testing (symptoms) ${ }^{\mathrm{u}}$} & & & \\
\hline & & & & & \multicolumn{2}{|c|}{ Apple } & \multicolumn{2}{|c|}{ Pear } & \multicolumn{3}{|c|}{ GenBank Accession } \\
\hline & & Location & Host/part & Symptoms $^{w}$ & Shoot & Fruit & Shoot & Fruit & ITS & $\beta$-tublin & Actin \\
\hline \multicolumn{12}{|c|}{ Isolates from China } \\
\hline ALYGF & $\begin{array}{l}\text { Botryosphaeria } \\
\text { dothidea }\end{array}$ & Beijing & Apple/twig & Dieback & Wart &..$^{\mathrm{x}}$ &.$\cdot$ & .. & JF440896 &.$\cdot$ & .. \\
\hline $\mathrm{CP} 1 *$ & B. dothidea & Beijing & Apple/branch & Wart & Wart & .. & .. &.. & JF440900 & .. & .. \\
\hline $\mathrm{CP} 2 *$ & B. dothidea & Beijing & Apple/branch & Wart & Wart & .. & .. & .. & JF440901 & .. & .. \\
\hline 78-3ZHI* & B. dothidea & Henan & Apple/branch & Wart & Wart &.. & .. & .. & JF440853 & JF440852 & JF440912 \\
\hline HPLW1* & B. dothidea & Henan & Pear/branch & Wart & Wart & .. & .. & .. & JF440890 & JF440840 & JF440940 \\
\hline $\mathrm{HX} 1 *$ & B. dothidea & Henan & Apple/branch & Wart & Wart &.. & .. & .. & JF440858 & JF440815 & JF440915 \\
\hline MQ5* & B. dothidea & Henan & Apple/branch & Wart & Wart &.. & .. & .. & JF440862 & JF440818 & JF440918 \\
\hline MZ53* & B. dothidea & Henan & Apple/branch & Wart & Wart &.. & .. &.. & JF440864 & JF440820 & JF440920 \\
\hline SM12 & B. dothidea & Henan & Apple/branch & Wart &.. & .. & .. & .. & JF440881 &.. &.. \\
\hline SM5* & B. dothidea & Henan & Apple/branch & Wart & Wart &.. &.. & .. & JF440873 &.. &.. \\
\hline ZZ3* & B. dothidea & Henan & Apple/branch & Wart & Wart & Lesion & Wart & .. & JF440883 & JF440834 & JF440934 \\
\hline 78-3GUO* & B. dothidea & Henan & Apple/fruit & Lesion & Wart &.. &.. & .. & JF440854 & JF440812 & JF440913 \\
\hline MQ15* & B. dothidea & Henan & Apple/fruit & Lesion & Wart &.. & .. & .. & JF440863 & JF440819 & JF440919 \\
\hline MZ55* & B. dothidea & Henan & Apple/fruit & Lesion & Wart & .. & .. & .. & JF440865 & JF440821 & JF440921 \\
\hline PY35 & B. dothidea & Henan & Apple/fruit & Lesion &.. & .. & .. & .. & JF440869 &.. &.. \\
\hline PY37 & B. dothidea & Henan & Apple/fruit & Lesion & .. &.. & .. &.. & JF440875 &.. &.. \\
\hline QF20 & B. dothidea & Henan & Apple/fruit & Lesion & Wart &.. & .. &.. & JF440872 & JF440827 & JF440927 \\
\hline ZM12 & B. dothidea & Henan & Apple/fruit & Lesion &.. &.. &.. &.. & JF440880 & JF440832 & JF440932 \\
\hline NY20 & B. dothidea & Henan & Pear/branch & Wart & Wart &.. & Wart &.. & JF440867 & JF440823 & JF440923 \\
\hline NL1* & B. dothidea & Henan & Pear/branch & Wart & Wart & Lesion & Wart & Lesion & JF440878 & JF440830 & JF440930 \\
\hline PY2 & B. dothidea & Henan & Apple/branch & Wart & Wart &.. & Wart &.. & JF440868 & JF440824 & JF440924 \\
\hline PY29 & B. dothidea & Henan & Apple/branch & Wart &.. &.. &.. & .. & JF440870 & JF440825 & JF440925 \\
\hline QF2 & B. dothidea & Henan & Apple/branch & Wart & Wart & .. & Wart & .. & JF440871 & JF440826 & JF440926 \\
\hline WS11* & B. dothidea & Henan & Apple/branch & Wart & Wart & .. &.. & .. & JF440874 &.. &.. \\
\hline YC11 & B. dothidea & Henan & Apple/branch & Wart & Wart &.. & .. & .. & JF440877 & JF440829 & JF440929 \\
\hline YC5 & B. dothidea & Henan & Apple/branch & Canker & Wart &.. & .. & .. & JF440908 & JF440851 & JF440951 \\
\hline ZM20* & B. dothidea & Henan & Pear/branch & Canker & Wart & Lesion & .. & .. & JF440891 & JF440841 & JF440941 \\
\hline $\mathrm{ZZ2} *$ & B. dothidea & Henan & Apple/branch & Wart & Wart & Lesion & Wart & .. & JF440882 & JF440833 & JF440933 \\
\hline G61* & B. dothidea & Liaoning & Apple/fruit & Lesion & Wart & Lesion &.. & .. & JF501218 &.. &.. \\
\hline GZ29 & B. dothidea & Liaoning & Apple/fruit & Lesion &.. &.. & .. & .. & JF440885 &.. &.. \\
\hline L19* & B. dothidea & Liaoning & Apple/fruit & Lesion & Wart &.. & .. & .. & JF440892 & JF440842 & JF440942 \\
\hline LG05* & B. dothidea & Liaoning & Apple/fruit & Lesion & Wart & .. & .. & .. & JF440895 & .. &.. \\
\hline LW045* & B. dothidea & Liaoning & Apple/fruit & Lesion & Wart &.. &.. & .. & JF440911 &.. & .. \\
\hline HL1* & B. dothidea & Liaoning & Apple/branch & Wart & Wart & Lesion & Wart & .. & JF440857 & JF440814 & JF440914 \\
\hline $\mathrm{LS} 1 *$ & B. dothidea & Shandong & Apple/branch & Wart & Wart & Lesion & .. &.. & JF440859 & JF440816 & JF440916 \\
\hline LW018* & B. dothidea & Shandong & Apple/fruit & Lesion & Wart & Lesion & Wart & Lesion & JF440861 & JF440817 & JF440917 \\
\hline LXS041502* & B. dothidea & Shandong & Apple/fruit & Lesion & Wart & Lesion & Wart & Lesion & JF440887 &.. &.. \\
\hline LXS130103* & B. dothidea & Shandong & Pear/fruit & Lesion & Wart & Lesion & Wart & Lesion & JF440902 & JF440846 & JF440946 \\
\hline WG-1* & B. dothidea & Shandong & Apple/fruit & Lesion & Wart & Lesion &.. &.. & JF440904 & JF440848 & JF440948 \\
\hline $15^{*}$ & B. dothidea & Shandong & Apple/branch & Canker & Wart & Lesion & .. & .. & JF440889 & JF440839 & JF440939 \\
\hline G1* & B. dothidea & Shandong & Apple/branch & Canker & $-\mathrm{y}$ & - & - & - & JF440903 & JF440847 & JF440947 \\
\hline LW023 & B. dothidea & Shandong & Apple/branch & Wart & Wart & Lesion & .. &.. & JF440888 & JF440838 & JF440938 \\
\hline LXS030103 & B. dothidea & Shandong & Apple/branch & Canker &.. &.. & .. & .. & JF440876 & JF440828 & JF440928 \\
\hline LXS030201* & B. dothidea & Shandong & Apple/branch & Canker & Wart & Lesion & .. & .. & JF440856 &.. &.. \\
\hline LXS030202 & B. dothidea & Shandong & Apple/branch & Canker &.. &.. &.. &.. & JF440879 & JF440831 & JF440931 \\
\hline $\mathrm{LXS} 030301^{\mathrm{Z}} *$ & B. dothidea & Shandong & Apple/branch & Canker & Wart & Lesion & Wart & Lesion & JF440855 & JF440813 & JF440952 \\
\hline LXS041701* & B. dothidea & Shandong & Apple/branch & Wart & Wart & Lesion &.. &.. & JF440884 & JF440835 & JF440935 \\
\hline LXS170101* & B. dothidea & Shandong & Pear/branch & Canker & Wart & Lesion & Wart/canker & Lesion & JF440898 & JF440845 & JF440945 \\
\hline LDR4-1* & B. dothidea & Shanxi & Apple/branch & Wart &.. &.. & .. &.. & JF440860 & .. & .. \\
\hline LCP1-1 & B. dothidea & Shanxi & Apple/branch & Wart &.. &.. & .. &.. & JF501219 & .. &.. \\
\hline $0029 *$ & B. dothidea & Shaanxi & Apple/fruit & Lesion & Wart & Lesion &.. & .. & JF440905 & .. & .. \\
\hline $0086^{*}$ & B. dothidea & Shaanxi & Apple/fruit & Lesion & Wart & Lesion &.. &.. & JF440894 &.. &.. \\
\hline YL1* & B. dothidea & Shaanxi & Apple/fruit & Lesion & Wart & Lesion & Wart & Lesion & JF440886 & JF440837 & JF440937 \\
\hline $\mathrm{NK} 2 *$ & B. dothidea & Tianjin & Apple/fruit & Lesion & Wart & Lesion &.. &.. & JF440866 & JF440822 & JF440922 \\
\hline KMAF1 & B. dothidea & Yunnan & Apple/fruit & Lesion &.. &.. & .. & .. & JF440909 &.. &.. \\
\hline KMAF2 & B. dothidea & Yunnan & Apple/fruit & Lesion &.. & .. & .. & .. & JF440910 & .. &.. \\
\hline KMAB1* & B. dothidea & Yunnan & Apple/branch & Wart & Wart & .. & .. & .. & JF501231 &.. &.. \\
\hline & & & & & & & & & & (continu & nn next page \\
\hline
\end{tabular}

u Symptom shown on unwounded shoots or fruit in the pathogenicity test in this study; the corresponding disease incidence of the same test was shown in Table 2.

${ }^{v}$ CFCC $=$ China Forestry Culture Collection Center, Beijing, China; CBS = Centraalbureau voor Schimmelcultures, Utrecht, The Netherlands; CMW = MJ Wingfield, FABI, University of Pretoria, South Africa. Isolates with * produced abundant conidia and were used in the measurement of conidial size.

${ }^{\mathrm{w}}$ Lesion on fruit is characterized as slightly sunken lesions with alternating tan and brown rings (Fig. 1A). Warts are distinguished from cankers by their appearance. Warts are small, rounded protuberances usually 5 to $7 \mathrm{~mm}$ in diameter and 2 to $3 \mathrm{~mm}$ in height formed on the branch (Fig 1B). Cortex and vascular tissue under the wart are not necrotic. Canker on branch refers to sunken lesion with discoloration of cortex and vascular tissue which may extend beyond the sunken area (Fig. $1 \mathrm{~F}$ and $\mathrm{G}$ and Fig. 5).

${ }^{x}$ Not tested in this study.

y No symptoms observed.

${ }^{\mathrm{z}}$ Single-ascospore isolate. 


\begin{tabular}{|c|c|c|c|c|c|c|c|c|c|c|c|}
\hline \multirow[b]{3}{*}{ Isolates $^{v}$} & \multirow[b]{3}{*}{ Species } & & & & \multicolumn{4}{|c|}{ Pathogenicity testing (symptoms) ${ }^{\mathrm{u}}$} & & & \\
\hline & & \multicolumn{3}{|c|}{ Origin } & \multicolumn{2}{|c|}{ Apple } & \multicolumn{2}{|c|}{ Pear } & \multicolumn{3}{|c|}{ GenBank Accession } \\
\hline & & Location & Host/part & Symptoms $^{w}$ & Shoot & Fruit & Shoot & Fruit & ITS & $\beta$-tublin & Actin \\
\hline \multicolumn{12}{|c|}{ Reference isolates } \\
\hline CFCC5296 & B. dothidea & Beijing & Walnut & Unknown & - & .. & - & .. & JF501220 & .. & .. \\
\hline CFCC7918* & B. dothidea & Henan & Peach & Unknown & - &.. & - & .. & JF501222 & .. & .. \\
\hline CFCC6882 & B. dothidea & Henan & Populus & Unknown & - & Lesion & - & .. & JF501223 & .. & .. \\
\hline CFCC80881 & B. dothidea & Shandong & Chestnut & Unknown & - &.. & - & .. & JF501225 &.. &.. \\
\hline m-D1-1 & $\begin{array}{l}\text { B. berengeriana } \\
\text { f. sp. piricola }\end{array}$ & Japan & Pear/fruit & Lesion & - & - & - & - & JF501226 & JF501227 & JF501229 \\
\hline $3 \mathrm{~K}^{*}$ & B. dothidea & Korea & Apple/fruit & Lesion & Wart & Lesion & Wart & Lesion & JF440906 & JF440849 & JF440949 \\
\hline $5 \mathrm{~K}^{*}$ & B. dothidea & Korea & Apple/fruit & Lesion & Wart &.. & .. & .. & JF440893 & JF440843 & JF440943 \\
\hline CBS118822 & $\begin{array}{l}\text { Neofusicoccum } \\
\text { ribis }\end{array}$ & $\begin{array}{l}\text { South } \\
\text { Africa }\end{array}$ & $\begin{array}{l}\text { Syzygium } \\
\text { cordatum/ } \\
\text { unknown }\end{array}$ & Unkown & - & Lesion & - & Lesion & DQ316072 & JF440836 & JF440936 \\
\hline CBS115476* & B. dothidea & Switerland & $\begin{array}{l}\text { Prunus sp./ } \\
\text { unknown }\end{array}$ & Unknown & - & Lesion & - & Lesion & AY236949 & AY236927 & AY972118 \\
\hline $\mathrm{Bd} 1 *$ & B. dothidea & NC, USA & Apple/fruit & Lesion & Wart & .. & .. & .. & JF440907 & JF440850 & JF440950 \\
\hline Bd1862* & B. dothidea & $\mathrm{NC}$, USA & Apple/fruit & Lesion & Wart &.. &.. & .. & JF501221 &.. &.. \\
\hline Bd1864* & B. dothidea & $\mathrm{NC}$, USA & Apple/fruit & Lesion & Wart & Lesion & Wart & Lesion & JF440897 & JF440844 & JF440944 \\
\hline Bd1881* & B. dothidea & $\mathrm{NC}$, USA & Apple/fruit & Lesion & Wart & Lesion & Wart & Lesion & JF501224 & JF501228 & JF501230 \\
\hline $\mathrm{Bd} 2 *$ & B. dothidea & $\mathrm{NC}$, USA & Apple/fruit & Lesion &.. & .. &.. &.. & JF440899 &.. & .. \\
\hline \multicolumn{12}{|c|}{ Sequences used } \\
\hline CBS418.64 & B. tsugae & Canada & $\begin{array}{l}\text { Tsuga } \\
\quad \text { heterophylla }\end{array}$ & & & & & & DQ458888.1 & .. & .. \\
\hline CBS95397 & $\begin{array}{c}\text { Glomerella } \\
\text { cingulata }\end{array}$ & Italy & Citrus sinensis & & & & & & FJ972609.1 & FJ907445.1 & FJ907430.1 \\
\hline CAP247 & $\begin{array}{l}\text { Neofusicoccum } \\
\text { parvum }\end{array}$ & Italy & Olea europaea & & & & & & EF638786.1 & .. & .. \\
\hline Dsp2 & B. obtusa & Italy & Quercussuber & & & & & & DQ487159.1 & .. &.. \\
\hline CMW9074 & B. rhodina & Mexico & Pinus sp. & & & & & & AY236952 & AY236930 & AY972108 \\
\hline CMW7060 & B. stevensii & Netherlands & $\begin{array}{l}\text { Fraxinus } \\
\text { excelsior }\end{array}$ & & & & & & AY236955 & AY236933 & AY972112 \\
\hline WWF37 & $\begin{array}{c}\text { Lasiodiplodia } \\
\text { theobromae }\end{array}$ & USA & Blueberry & & & & & & GQ845099.1 & .. & .. \\
\hline UCR211 & B. lutea & USA & $\begin{array}{l}\text { Persea } \\
\text { americana }\end{array}$ & & & & & & GQ857658.1 & .. & .. \\
\hline UCR739 & $\begin{array}{l}\text { Neofusicoccum } \\
\text { australe }\end{array}$ & USA & P. americana & & & & & & GQ857662.1 & .. & .. \\
\hline CMW7772 & B. ribis & USA & Ribes sp. & & & & & & AY236935.1 & AY236906.1 & AY972115.1 \\
\hline $\begin{array}{l}\text { ATCC:MYA- } \\
4115\end{array}$ & B. viticola & USA & Unknown & & & & & & EU331079.1 &. &.. \\
\hline
\end{tabular}

shoots and fruits of apple and pear. The pathogenicity test on shoots was conducted in a nursery from May to July in 2008 and 2009 on new shoots on 1- to 2-year-old apple (Malus domestica 'Fuji') and pear (Pyrus pyrifolia 'Nakai') trees in an orchard (in Zhengzhou, Henan Province). For each isolate tested, five inoculations were made on a shoot, three shoots on a tree were used as one replicate, and three replicates were used for each isolate in a completely randomized design; controls were treated in a similar manner with noncolonized PDA plugs. The pathogenicity test on fruit was conducted both on detached fruit in the laboratory and on fruit in the orchard as indicated later. All experiments were repeated.

Pathogenicity on unwounded shoots. For inoculation of unwounded shoots, the portion of the shoot between leaves was disinfested with a cotton ball wetted with $70 \%$ ethyl alcohol before a mycelium plug ( $5 \mathrm{~mm}$ in diameter) cut from the margin of a 7-dayold culture was placed on the disinfested region and then covered with a sterile, moist cotton ball. The inoculation site was then wrapped with a piece of Parafilm to maintain high humidity. The same number of shoots inoculated similarly with PDA plugs without fungus was used as noninoculated controls. These methods were used to test the pathogenicity on apple shoots of 45 isolates from apple or pear in China and all 13 reference isolates. The pathogenicity of 25 isolates ( $23 \mathrm{~B}$. dothidea isolates, isolate m-D11 of $B$. berengeriana $\mathrm{f}$. sp. piricola, and isolate CBS118822 of $N$. ribis) was tested using the same procedures but on pear shoots rather than on apple shoots (Tables 1 and 2).

Unwounded shoots were also inoculated with spore suspensions of isolates YL1, LXS130103, and NL1. A cotton ball $(5 \mathrm{~mm}$ in diameter) soaked in a conidial suspension $\left(10^{4} \mathrm{ml}^{-1}\right)$ was placed on the disinfested shoot region and then wrapped with a piece of Parafilm. As a control, the cotton balls were moistened with sterile-distilled water only.

Pathogenicity on wounded shoots. For inoculation of wounded shoots, wounds (1.5 $\mathrm{mm}$ in diameter and $2 \mathrm{~mm}$ deep) were made on the shoots with a nail disinfested with $70 \%$ alcohol. A mycelial plug was immediately placed on the wound, which was then covered with a moist cotton ball and wrapped as described above. Wounded shoots inoculated with PDA plugs without fungus were used as controls. This method was used to test the pathogenicity of 23 isolates ( 21 isolates of $B$. dothidea, isolate m-D1-1 of B. berengeriana f. sp. piricola, and isolate CBS118822 of $N$. ribis) on apple shoots and of 14 isolates (including 12 isolates of $B$. dothidea, isolate m-D1-1 of $B$. berengeriana $\mathrm{f}$. sp. piricola, and isolate CBS118822 of N. ribis) on pear shoots (Table 3).

Pathogenicity on unwounded and wounded fruit. Pathogenicity was also tested on detached fruit with and without wounding in the laboratory. Mature apple (Fuji) and pear (Bretschneideri) fruit were washed, surface disinfested with $3.5 \% \mathrm{NaOCl}$ for $5 \mathrm{~min}$, rinsed twice with sterile-distilled water, and dried in a transfer hood. Five mycelial plugs ( $5 \mathrm{~mm}$ in diameter) cut from the margin of a 7-day-old culture were placed on the surface of each nonwounded fruit with an equal distance between adjacent plugs. Fruit inoculated with PDA plugs without fungus were used as controls. In total, 28 isolates ( 26 of $B$. dothidea, isolate m-D1- 1 of B. berengeriana f. sp. piricola, and isolate CBS118822 of $N$. ribis) were tested on apple fruit, while 14 isolates (12 of $B$. dothidea, isolate 
m-D1-1 of B. berengeriana f. sp. piricola, and isolate CBS118822 of the $N$. ribis) were tested on pear fruit (Tables 1 and 2). For inoculation of wounded fruit, fruit were handled in the same manner but the plugs were placed on wounds $(1.5 \mathrm{~mm}$ in diameter and $2 \mathrm{~mm}$ deep) made with a sterilized nail. In total, 13 isolates (11 of B. dothidea, isolate m-D1-1 of B. berengeriana $\mathrm{f}$. sp. piricola, and isolate CBS118822 of $N$. ribis) were tested on wounded apple fruit and 11 isolates (nine of $B$. dothidea, isolate m-D1-1 of $B$. berengeriana f. sp. piricola, and isolate CBS118822 of the N. ribis) were tested on wounded pear fruit (Table 3 ). Three fruit were used as a replicate, and three replicates were used for each combination of isolate and wounded or nonwounded treatment. Inoculated fruit were then kept in sterilized plastic boxes at $25^{\circ} \mathrm{C}$ in darkness. The entire experiment was repeated.

Table 2. Incidence of warts on unwounded shoots and lesions on unwounded fruit of apple and pear inoculated with isolates of Botryosphaeria dothidea and related species via the mycelium plug method

\begin{tabular}{|c|c|c|c|c|}
\hline \multirow[b]{3}{*}{ Isolate } & \multicolumn{4}{|c|}{ Incidence $(\%)^{\mathrm{y}}$} \\
\hline & \multicolumn{2}{|c|}{ Apple } & \multicolumn{2}{|c|}{ Pear } \\
\hline & Warts on shoot & Lesions on fruit & Warts on shoot & Lesions on fruit \\
\hline ALYGF & $18.9 \pm 11.5$ lmnopq &..$^{\mathrm{z}}$ &.. &.. \\
\hline CP1 & $34.4 \pm 19.1$ ijklmnop &.. &.. &.. \\
\hline $\mathrm{CP} 2$ & $40.0 \pm 39.1$ defghijklm &.. &.. &.. \\
\hline 78-3ZHI & $65.6 \pm 13.6$ bcdefgh &.. &.. &.. \\
\hline HPLW1 & $27.8 \pm 12.9$ klmnopq &.. &.. &.. \\
\hline HX1 & $62.2 \pm 30.6 \mathrm{abcd}$ &.. &.. &.. \\
\hline MQ5 & $45.6 \pm 12.2$ efghijklmn &.. &.. &.. \\
\hline MZ53 & $50.0 \pm 18.7$ defhijkl &.. &.. &.. \\
\hline SM5 & $41.1 \pm 20.0$ fghijklmnop & .. & .. &.. \\
\hline ZZ3 & $67.8 \pm 20.4$ abcdef & $82.2 \pm 3.4$ cdefg & $24.4 \pm 6.9 \mathrm{bcd}$ &.. \\
\hline 78-3GUO & $25.6 \pm 11.5 \mathrm{klmnopq}$ & .. & .. &.. \\
\hline MQ15 & $24.4 \pm 10.4$ klmnopq & .. & .. &.. \\
\hline MZ55 & $38.9 \pm 19.1$ ghijklmnop &.. &.. &.. \\
\hline QF20 & $37.8 \pm 29.4$ ghijklmnop &.. & .. &.. \\
\hline NY20 & $31.1 \pm 10.0$ ijklmnopq & .. & $17.8 \pm 15.6 \mathrm{cde}$ & .. \\
\hline NL1 & $28.9 \pm 16.2 \mathrm{jklmnopq}$ & $83.3 \pm 11.0$ bcde & $34.4 \pm 10.7 \mathrm{bc}$ & $60.0 \pm 20.2 \mathrm{cde}$ \\
\hline PY2 & $11.1 \pm 12.4 \mathrm{opq}$ & .. & $2.2 \pm 3.4 \mathrm{e}$ & .. \\
\hline QF2 & $43.3 \pm 18.3$ fghijklmnop &.. & $26.7 \pm 6.0 \mathrm{bcd}$ &.. \\
\hline WS11 & $20.0 \pm 11.9$ lmnopq &.. & .. &.. \\
\hline YC11 & $44.4 \pm 10.9$ fghijklmn &.. &.. &.. \\
\hline YC5 & $27.8 \pm 14.9$ klmnopq & .. &.. &.. \\
\hline ZM20 & $35.6 \pm 11.7$ ijklmnop & $75.6 \pm 13.8$ defghi & .. &.. \\
\hline $\mathrm{ZZ2}$ & $30.0 \pm 21.8 \mathrm{ijklmnopq}$ & $65.6 \pm 8.9$ hijkl & $7.8 \pm 7.8 \mathrm{de}$ &.. \\
\hline G61 & $45.6 \pm 21.7$ defghijklmn & $55.6 \pm 15.6 \mathrm{jkl}$ & .. &.. \\
\hline L19 & $65.6 \pm 30.8$ abcdef & .. &.. &.. \\
\hline LG05 & $16.7 \pm 13.8 \mathrm{mnopq}$ &.. &.. &.. \\
\hline LW045 & $80.0 \pm 22.3 \mathrm{a}$ & .. & .. &.. \\
\hline HL1 & $71.1 \pm 16.2$ abcde & $57.8 \pm 12.4 \mathrm{ijkl}$ & $11.1 \pm 9.1 \mathrm{de}$ &.. \\
\hline LS1 & $30.0 \pm 13.2$ ijklmnopq & $76.7 \pm 13.8$ defgh & .. & .. \\
\hline LW018 & $66.7 \pm 15.8$ abcdefg & $57.8 \pm 11.7 \mathrm{ijkl}$ & $41.1 \pm 20.8 \mathrm{ab}$ & $60.0 \pm 14.6 \mathrm{cdef}$ \\
\hline LXS041502 & $8.9 \pm 3.91 \mathrm{lmnopq}$ & $65.6 \pm 14.9$ ghijk & $13.3 \pm 16.3 \mathrm{de}$ & $56.7 \pm 12.5 \mathrm{defg}$ \\
\hline LXS130103 & $38.9 \pm 10.7$ hijklmnop & $72.2 \pm 12.2$ efghij & $36.7 \pm 23.8 \mathrm{bc}$ & $93.3 \pm 8.4 \mathrm{~b}$ \\
\hline WG-1 & $14.4 \pm 9.8$ nopq & .. & .. & .. \\
\hline 15 & $15.56 \pm 10.04$ mnopq & $61.1 \pm 12.9$ hijkl & .. & .. \\
\hline G1 & $0.0 \pm 0.0 \mathrm{q}$ & $0.0 \pm 0.00$ & $0.0 \pm 0.0 \mathrm{e}$ & $0.0 \pm 0.0 \mathrm{j}$ \\
\hline LW023 & $23.3 \pm 18.7 \mathrm{klmnopq}$ & $67.8 \pm 11.5$ fghijk & .. & .. \\
\hline LXS030301 & $38.9 \pm 10.7 \mathrm{ab}$ & $62.2 \pm 13.1$ hijkl & $50.0 \pm 26.9 \mathrm{a}$ & $44.4 \pm 13.1$ efghi \\
\hline LXS030201 & $26.7 \pm 16.9$ klmnopq & $62.2 \pm 14.4$ hijkl & .. & .. \\
\hline LXS041701 & $60.0 \pm 9.4$ cdefghij & $46.7 \pm 19.8 \mathrm{klm}$ & .. & .. \\
\hline LXS170101 & $34.4 \pm 19.5$ ijklmnop & $80.0 \pm 10.3$ bcdef & $11.1 \pm 5.4 \mathrm{de}$ & $46.7 \pm 10.3 \mathrm{efgh}$ \\
\hline 0029 & $64.4 \pm 32.0$ abcde & $92.2 \pm 6.6 \mathrm{~b}$ & .. & .. \\
\hline 0086 & $10.0 \pm 7.0 \mathrm{pq}$ & $47.8 \pm 10.7 \mathrm{klm}$ & .. & .. \\
\hline YL1 & $80.0 \pm 14.0 \mathrm{abc}$ & $84.4 \pm 10.0$ bcde & $43.3 \pm 13.8 \mathrm{ab}$ & $97.8 \pm 3.9 \mathrm{ab}$ \\
\hline NK2 & $31.1 \pm 24.5$ ijklmnopq & $60.0 \pm 11.9$ hijkl & .. & .. \\
\hline KMAB 1 & $46.7 \pm 28.6$ defhijk & .. & .. &.. \\
\hline CFCC5296 & $0.0 \pm 0.0 \mathrm{q}$ &.. & $0.0 \pm 0.0 \mathrm{e}$ &.. \\
\hline CFCC7918 & $0.0 \pm 0.0 \mathrm{q}$ & .. & $0.0 \pm 0.0 \mathrm{e}$ &.. \\
\hline CFCC6882 & $0.0 \pm 0.0 \mathrm{q}$ & $15.6 \pm 5.4$ no & $0.0 \pm 0.0 \mathrm{e}$ & .. \\
\hline CFCC80881 & $0.0 \pm 0.0 \mathrm{q}$ & .. & $0.0 \pm 0.0 \mathrm{e}$ & .. \\
\hline m-D1-1 & $0.0 \pm 0.0 \mathrm{q}$ & $0.0 \pm 0.00$ & $0.0 \pm 0.0 \mathrm{e}$ & $0.0 \pm 0.0 \mathrm{j}$ \\
\hline $3 \mathrm{~K}$ & $75.6 \pm 25.9 \mathrm{ab}$ & $84.4 \pm 15.0 \mathrm{bcd}$ & $10.0 \pm 15.6 \mathrm{de}$ & $44.4 \pm 20.5$ efghi \\
\hline $5 \mathrm{~K}$ & $41.1 \pm 19.1$ fghijklmnop & .. & .. & .. \\
\hline CBS118822 & $0.0 \pm 0.0 \mathrm{q}$ & $100.0 \pm 0.00 \mathrm{a}$ & $0.0 \pm 0.0 \mathrm{e}$ & $100.0 \pm 0.0 \mathrm{a}$ \\
\hline CBS115476 & $0.0 \pm 0.0 \mathrm{q}$ & $17.8 \pm 12.4$ no & $0.0 \pm 0.0 \mathrm{e}$ & $24.4 \pm 15.6 \mathrm{i}$ \\
\hline $\mathrm{Bd} 1$ & $37.4 \pm 24.1$ hijklmnop & .. & .. & .. \\
\hline Bd1862 & $60.0 \pm 17.9$ cdefgh & .. & .. & .. \\
\hline Bd1864 & $60.0 \pm 14.0$ cdefghi & $57.8 \pm 14.4 \mathrm{ijkl}$ & $33.3 \pm 15.2 \mathrm{bc}$ & $51.1 \pm 13.8$ defgh \\
\hline Bd1881 & $41.1 \pm 21.3$ fghijklmnop & $88.9 \pm 10.0 \mathrm{bc}$ & $17.8 \pm 13.8 \mathrm{cde}$ & $68.9 \pm 25.2 \mathrm{c}$ \\
\hline
\end{tabular}

y Values are means $( \pm \mathrm{SE})$ of two repeated experiments. Means with the same letter are not significantly different at the 0.05 level. Incidence of warts or lesions was calculated as percentage of 15 inoculation sites.

z Not tested in this study. 
Mature apple fruit in an orchard (located in Yantai, Shandong Province) were inoculated with conidia of isolate YL1, LXS130103, and NL1. For each isolate, 15 fruit on each of three healthy Fuji trees (approximately 6 years old) were inoculated as a replicate. A conidial suspension $\left(10^{4} \mathrm{ml}^{-1}\right)$ was sprayed on the surface of the apple fruit 10 days before harvest. After they were harvested, fruit were incubated at $25^{\circ} \mathrm{C}$ and inspected periodically. The experiment was repeated.

Reisolation and identification of infected fungi. Fungi were isolated from diseased parts of inoculated shoots and fruit to complete Koch's postulates. Warts or edges of the lesions were surface disinfested in $3.5 \% \mathrm{NaOCl}$ for $30 \mathrm{~s}$, washed in sterile-distilled water twice, and then kept on PDA in dishes at $25^{\circ} \mathrm{C}$ for 7 days. Fungi were identified based on conidial morphology and the sequence of the rDNA ITS region as described previously.

Statistical analyses. For each pathogenicity test, disease incidence was calculated as the percentage of the inoculation site showing wart, lesion, or decay symptoms in each replicate. Data from repeated tests and among treatments in each test were compared using analysis of variance (ANOVA) in SAS software (SAS Institute, Cary, NC). Data were arcsine transformed before analyses to improve homogeneity of variance. Means between treatments in each test were compared using the Fisher's least significant difference (LSD) at the 5\% significance level. When a significant difference was not found between data of two repeated tests, the data from the repeated experiments were combined and analyzed together $(n=6)$; this was the case for all repetitions of all pathogenicity tests.

\section{Results}

Isolate characterization. On PDA or MEA, colonies formed by all isolates were initially greenish-brown to gray and then turned dark gray after 5 days of incubation. Pycnidia containing fusiform, hyaline, and aseptate conidia were produced by most isolates after 7 days at $25^{\circ} \mathrm{C}$ under near UV light. Occasionally, conidia with 1 to 3 septa were observed. The size of the fusicoccum conidia of 46

Table 3. Incidence of lesions on wounded shoots and wounded fruit of apple and pear inoculated with isolates of Botryosphaeria dothidea and related species via the mycelium plug method

\begin{tabular}{|c|c|c|c|c|}
\hline \multirow[b]{3}{*}{ Isolate } & \multicolumn{4}{|c|}{ Incidence $(\%)^{\mathrm{y}}$} \\
\hline & \multicolumn{2}{|c|}{ Apple } & \multicolumn{2}{|c|}{ Pear } \\
\hline & Lesions on shoots & Lesions on fruit & Lesions on shoots & Lesions on fruit \\
\hline ALYGF & $93.3 \pm 7.3 \mathrm{bcd}$ &..$^{z}$ & $96.7 \pm 5.6 \mathrm{a}$ & .. \\
\hline 78-3ZHI & $95.6 \pm 5.4 \mathrm{bc}$ & .. & $100.0 \pm 0.0 \mathrm{a}$ & .. \\
\hline HX1 & $100.0 \pm 0.0 \mathrm{a}$ & .. & & .. \\
\hline $\mathrm{ZZ3}$ & $100.0 \pm 0.0 \mathrm{a}$ & .. & $100.0 \pm 0.0 \mathrm{a}$ & .. \\
\hline NL1 & $100.0 \pm 0.0 \mathrm{a}$ & $100.0 \pm 0.0 \mathrm{a}$ & $96.7 \pm 5.6 \mathrm{a}$ & $100.0 \pm 0.0 \mathrm{a}$ \\
\hline ZZ2 & $96.7 \pm 3.7 \mathrm{abc}$ & .. &.. & .. \\
\hline LS1 & $100.0 \pm 0.0 \mathrm{a}$ & .. & .. & .. \\
\hline LW018 & $100.0 \pm 0.0 \mathrm{a}$ & $100.0 \pm 0.0 \mathrm{a}$ & .. & $100.0 \pm 0.0 \mathrm{a}$ \\
\hline LXS041502 & $92.2 \pm 5.0 \mathrm{~cd}$ & $100.0 \pm 0.0 \mathrm{a}$ & .. & .. \\
\hline LXS130103 & $100.0 \pm 0.0 \mathrm{a}$ & $100.0 \pm 0.0 \mathrm{a}$ & $100.0 \pm 0.0 \mathrm{a}$ & $100.0 \pm 0.0 \mathrm{a}$ \\
\hline 15 & $100.0 \pm 0.0 \mathrm{a}$ & & & \\
\hline G1 & $80.0 \pm 17.8 \mathrm{e}$ & $61.1 \pm 14.3 b$ & $52.2 \pm 29.3 \mathrm{c}$ & $100.0 \pm 0.0 \mathrm{a}$ \\
\hline LXS030301 & $100.0 \pm 0.0 \mathrm{a}$ & $100.0 \pm 0.0 \mathrm{a}$ & $100.0 \pm 0.0 \mathrm{a}$ & .. \\
\hline LXS030201 & $96.7 \pm 8.2 \mathrm{ab}$ & .. & & $100.0 \pm 0.0 \mathrm{a}$ \\
\hline LXS170101 & $93.3 \pm 7.3 \mathrm{bcd}$ & $100.0 \pm 0.0 \mathrm{a}$ & $100.0 \pm 0.0 \mathrm{a}$ & $100.0 \pm 0.0 \mathrm{a}$ \\
\hline YL1 & $100.0 \pm 0.0 \mathrm{a}$ & $100.0 \pm 0.0 \mathrm{a}$ & $100.0 \pm 0.0 \mathrm{a}$ & .. \\
\hline NK2 & $88.9 \pm 11.7 \mathrm{de}$ & & & $100.0 \pm 0.0 \mathrm{a}$ \\
\hline m-D1-1 & $0.0 \pm 0.0 \mathrm{~g}$ & $0.0 \pm 0.0 \mathrm{c}$ & $0.0 \pm 0.0 \mathrm{~d}$ & $0.0 \pm 0.0 \mathrm{~b}$ \\
\hline $3 \mathrm{~K}$ & $100.0 \pm 0.0 \mathrm{a}$ & & $100.0 \pm 0.0 \mathrm{a}$ & $100.0 \pm 0.0 \mathrm{a}$ \\
\hline CBS118822 & $100.0 \pm 0.0 \mathrm{a}$ & $100.0 \pm 0.0 \mathrm{a}$ & $66.7 \pm 36.5 b$ & $100.0 \pm 0.00 \mathrm{a}$ \\
\hline CBS115476 & $46.7 \pm 9.4 \mathrm{f}$ & $100.0 \pm 0.0 \mathrm{a}$ & $71.1 \pm 23.0 \mathrm{~b}$ & $100.0 \pm 0.0 \mathrm{a}$ \\
\hline $\mathrm{Bd} 1$ & $100.0 \pm 0.0 \mathrm{a}$ & $100.0 \pm 0.0 \mathrm{a}$ & & .. \\
\hline Bd1864 & $100.0 \pm 0.0 \mathrm{a}$ & $98.9 \pm 2.7 \mathrm{a}$ & $100.0 \pm 0.0 \mathrm{a}$ & $100.0 \pm 0.0 \mathrm{a}$ \\
\hline
\end{tabular}

${ }^{y}$ Values are means $( \pm$ SE) of two repeated experiments. Means with the same letter are not significantly different at the 0.05 level. Incidence of lesions was calculated as the percentage of 15 inoculation sites.

${ }^{z}$ Not tested in this study.

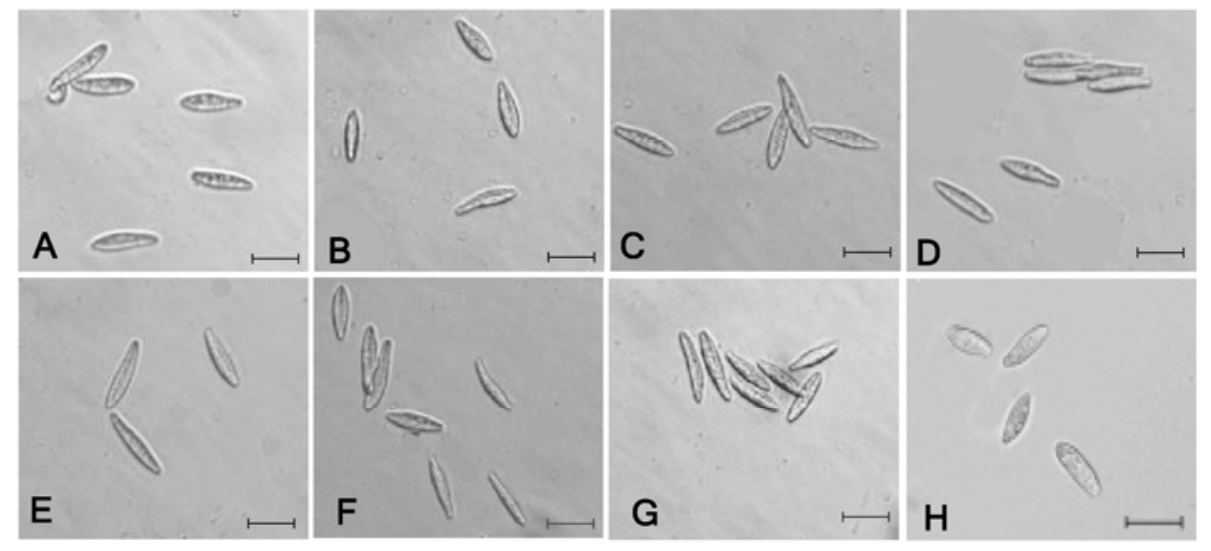

Fig. 2. Conidium morphology of apple ring rot pathogen from China and the reference isolates of Botryosphaeria dothidea and Neofusicoccum ribis. $\mathbf{A}$ to $\mathbf{C}$ are reference isolates of $B$. dothidea. D to $\mathbf{G}$ are isolates from China. $\mathbf{H}$ is reference isolates of N. ribis. A, CBS115476. B, 3K. C, Bd1. D, LW018. E, LXS130103. F, LXS030301. G, LXS170101. H, CBS118822. Scale bars $=20 \mu \mathrm{m}$. 
isolates that produced abundant of spores was (18.0-) 24.9-26.4 $(-35.0) \times(5.0-) 7.2-7.3(-8.5) \mu \mathrm{m} ; \mathrm{L} / \mathrm{W}=3.60 \pm 0.3$. Both the shape and the size of conidia of the measured isolates were similar to those of the conidia produced by the reference isolates of $B$. dothidea (Fig. 2), and were consistent with the description of Fusicoccum aesculi, the anamorph of $B$. dothidea $(9,31,32)$. These conidial measurements, however, differed from those of isolate
CBS118822 of $N$. ribis, which were (12.5-) 18.0-19.0 (-21.0) $\times$ (4.6-) 5.2-5.4 (-6.1) $\mu \mathrm{m}, \mathrm{L} / \mathrm{W}=3.50 \pm 0.4$. Isolate m-D1-1 of $B$. berengeriana $\mathrm{f}$. sp. piricola did not form pycnidia on MEA or PDA in this study.

Phylogenetic analysis. The ITS region of 69 of 71 isolates tested was successfully amplified, and the PCR products ranged from 550 to $560 \mathrm{bp}$. The ITS sequence of the two reference isolates

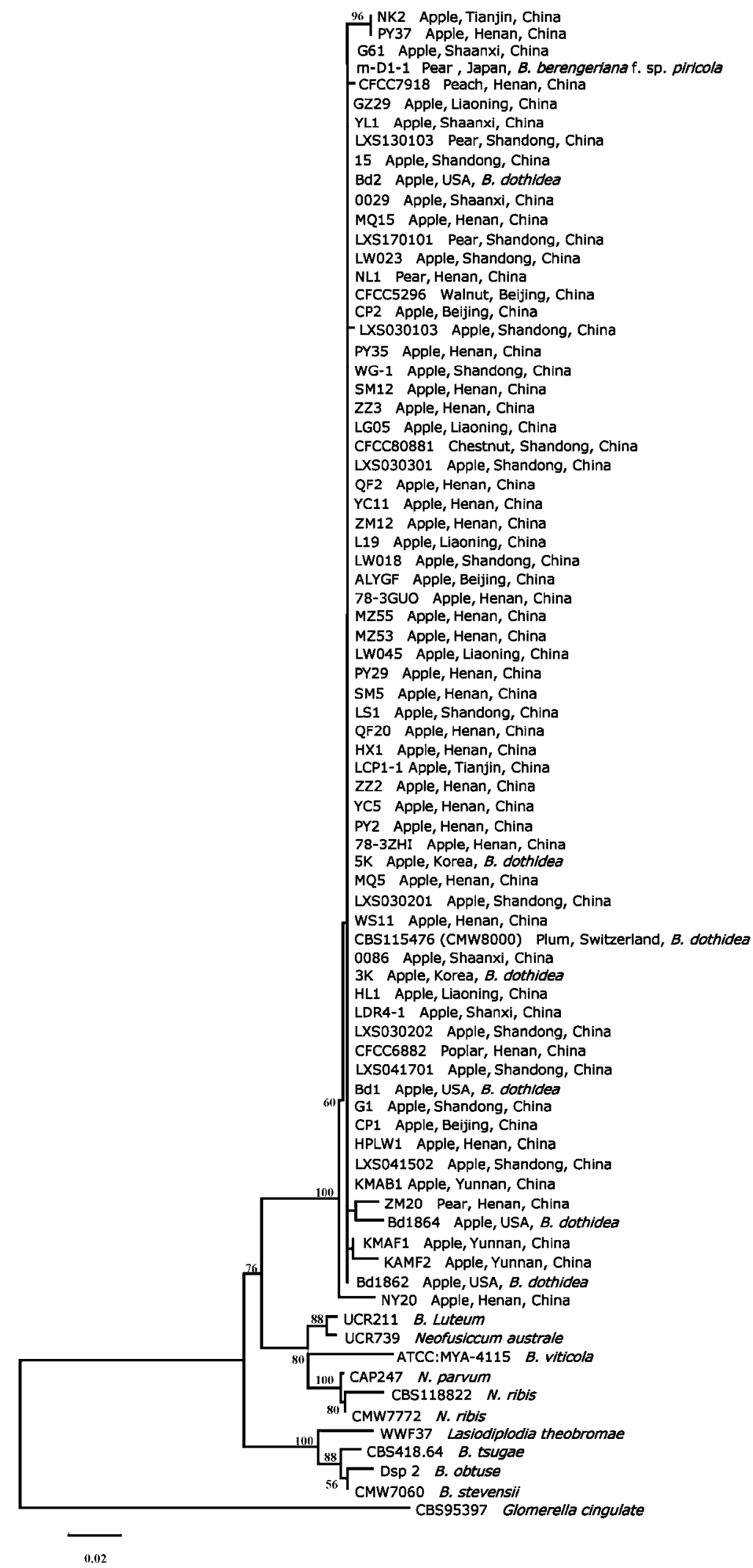

Fig. 3. Minimum-evolution analysis based on internal transcribed spacer region. Heuristic search with bootstrap value of 1,000 replications. Distance scale $=0.02$. 
of B. dothidea from CBS (CBS115476 and CBS118822) were retrieved from GenBank. All the ITS rDNA sequences of isolates from apple and pear in China, regardless of the type of disease tissue they were isolated from, were nearly identical to sequences of AY236949 of CBS115476, Bd1864, and Bd1 from the United States, $3 \mathrm{~K}$ and $5 \mathrm{~K}$ from South Korea, and m-D1-1 of B. berengeriana f. sp. piricola (Fig. 3). All the ITS rDNA sequences of isolates from apple and pear in China, however, were significantly different from sequences from isolates of other Botryosphaeria spp. and of N. ribis (Fig. 3).

The $\beta$-tubulin gene and the actin gene were successfully amplified for 44 isolates. Products ranged from 410 to $420 \mathrm{bp}$ for the $\beta$ tubulin gene and from 210 to $220 \mathrm{bp}$ for the actin gene. Sequence analysis of these products revealed a high similarity (>98\%) with the $\beta$-tubulin gene and the actin gene regions of the $B$. dothidea reference isolates. The combined sequences of the three regions contained 1,107 characters, in which 1,003 were constant, 91 were variable (43 were parsimony informative), and 13 were gaps or missing data. The phylogenetic analysis based on the combined sequences also showed that all the isolates from apple and pear in China had at least $98 \%$ similarity with those of the $B$. dothidea reference isolates but were significantly different from those of other species of Botryosphaeria and of $N$. ribis (Supplemental Fig. $1)$. The combined sequences of the three genes of $B$. berengeriana f. sp. piricola were identical to sequences of CBS115476, Bd1881, and $\mathrm{Bd} 1$ from the United States, $3 \mathrm{~K}$ and $5 \mathrm{~K}$ from South Korea, and most of the isolates from apple and pear in China tested. Therefore, the 50 isolates from apple and pear in China were identified as $B$. dothidea.

Pathogenicity tests. Disease incidence data from the two repetitions of each pathogenicity test were not significantly different $(P$ $\geq 0.05$ ). Therefore, data from the two repetitions of each experiment were combined and analyzed together $(n=6)$.

Pathogenicity on unwounded shoots. Warts, which are characterized as small, rounded protuberances $(0.4$ to $2.7 \mathrm{~mm}$ in diameter and 0.2 to $2.2 \mathrm{~mm}$ in height) without inner discoloration formed on the shoot epidermis or periderm, were commonly visible on apple shoots 40 to 60 days after inoculation with mycelium plugs of $B$. dothidea isolates (Fig. 4). The incidence of wart formation ranged from 0 to $80.0 \%$ and significantly differed among the isolates $(P<0.0001)$ (Fig. 4, Table 2). Among the isolates tested, all the $B$. dothidea isolates from apple and pear in China (except isolate G1), Korea, and the United States induced warts on apple shoots. No warts or other symptoms were produced on apple shoots inoculated with isolate G1 from apple in China, five isolates of $B$. dothidea not from apple or pear, isolate m-D1-1 of B. berengeriana $\mathrm{f}$. sp. piricola, isolate CBS118822 of $N$. ribis, or with plain agar plugs. $B$. dothidea was reisolated from the warts, while no pathogens were isolated from the asymptomatic tissue of the inoculation site or from the asymptomatic tissue of the controls. As the infection progressed, the number of warts usually increased, and the warts cracked; part of the periderm around the warts separated 4 to 12 months after inoculation.

Warts also formed on apple shoots 50 days after inoculation with conidia of three isolates. Wart incidence ranged from 6.7 to $26.7 \%$ depending on the isolate. $B$. dothidea was reisolated from the warts but not from the asymptomatic tissue of inoculated sites or from the asymptomatic tissue of the controls.

On pear shoots inoculated with mycelium plugs, all the tested $B$. dothidea isolates from apple or pear in China (except isolate G1), Korea, and the United States induced warts 50 days after inoculation. Wart incidence ranged from 2.2 to $50.0 \%$ on these shoots and significantly differed among the isolates $(P<0.0001)$. Isolate LXS170101 occasionally caused splitting of the periderm on shoots. No warts or other symptoms were produced on shoots that were inoculated with isolate $\mathrm{G} 1$, isolates of $B$. dothidea from other hosts, isolate CBS118822 of $N$. ribis, or with uncolonized agar plugs (Tables 1 and 2, Fig. 4). B. dothidea was reisolated from the warts and the split periderm tissues but not from the asymptomatic tissues of inoculated sites or the asymptomatic tissues of controls.
Pathogenicity on wounded shoots. A small, necrotic, and often sunken lesion with discoloration of cortex and vascular tissue occurred on apple and pear shoots 20 days after inoculation, although callus formation on the wound was occasionally observed at this time. All tested isolates, including isolates of $B$. dothidea from various hosts and isolates CBS118822 of $N$. ribis, but not m-D1-1 of $B$. berengeriana $\mathrm{f}$. sp. piricola, induced lesion formation on wounded apple shoots (Table 3, Fig. 5) and pear shoots (Table 3, Fig. 5). Disease incidence ranged from 46.7 to $100 \%$ and significantly differed among isolates $(P<0.0001)$. Isolate $\mathrm{G} 1$, which did not cause any symptoms on nonwounded shoots or fruit, induced lesion formation on wounded apple and pear shoots. Pathogens were reisolated from the diseased tissue but not from asymptomatic tissues.

Pathogenicity on unwounded fruit. When inoculated with mycelium plugs, all the isolates tested except G1 and m-D1-1 induced lesions on unwounded apple and pear fruit. The disease incidence ranged from 15.6 to $100 \%$ depending on the isolate, and significantly differed among the isolates $(P<0.0001)$ (Table 2$)$. Among the apple and pear fruit that were inoculated with PDA plugs, isolates $\mathrm{G} 1$ and $\mathrm{m}-\mathrm{D} 1-1$ of $B$. berengeriana $\mathrm{f}$. sp. piricola did not show any symptoms till the end of test. Frequently, a brown lesion with alternating $\tan$ and brown rings around the inoculation site was observed 3 to 5 days after inoculation (Fig. 6). The lesion expanded quickly and destroyed the entire fruit within 11 to 15 days. However, isolate CBS118822 destroyed the entire fruit within 4 days.

When unwounded apple fruit were inoculated with spores, lesions formed 15 days after inoculation, and the disease incidence ranged from 3.0 to $28.6 \%$ and significantly differed among the isolates $(P<0.0001)$. Pathogens were reisolated from the diseased tissues of these inoculated fruit but not from the asymptomatic tissue of the inoculation sites or the asymptomatic tissue of controls.

Pathogenicity on wounded fruit. All isolates tested except mD1-1 caused lesions on wounded apple and pear fruit (Table 3) 2 to 3 days after inoculation. Disease incidence ranged from 61.1 to $100 \%$ on apple fruit depending on the isolate and significantly differed among the isolates $(P<0.0001)$. However, the disease incidence was $100 \%$ for all the isolates tested on pear (Table 3). The lesions expanded quickly and destroyed the entire fruit within 11 to 15 days, but isolate CBS118822 destroyed the entire fruit within 3 days. Fruit that were inoculated with PDA plugs without fungi or with isolate m-D1-1 remained healthy. Pathogens were reisolated from the diseased tissue of the inoculated fruit but not from the asymptomatic tissue of the inoculated fruit or controls.

\section{Discussion}

The morphological observations, pathogenicity tests, and phylogenetic analyses based on gene sequences indicated that the causal agent of apple ring rot (both fruit rot and warts on branches) and Botryosphaeria canker of apple in China was $B$. dothidea. It was the same fungus that has been determined to be the causal agent of apple ring rot in South Korea (17) and Japan $(18,21)$ and of white rot of apple in North America $(4,16)$. These results also confirmed our hypothesis that the symptom of warts associated with apple ring rot and the symptom referred to as Botryosphaeria canker on apple branches in China were caused by the same pathogen and should be considered as different manifestations of the same disease. Our results also demonstrated that $B$. dothidea was the causal agent of pear ring rot and Botryosphaeria canker of pear. Isolates of $B$. dothidea from pear could attack both the fruit and the branches of apple.

Although the isolate of $B$. berengeriana $\mathrm{f}$. sp. piricola from Japan was not pathogenic on apple, both the morphology of the culture and the analysis of multiple gene sequences suggested that it belonged to $B$. dothidea. Its pathogenicity may have been lost during long-term storage. Because $B$. dothidea is not a quarantine pest and is a common pathogen on many pome fruits in the European Union, the quarantine status of $B$. berengeriana $\mathrm{f}$. sp. piricola 

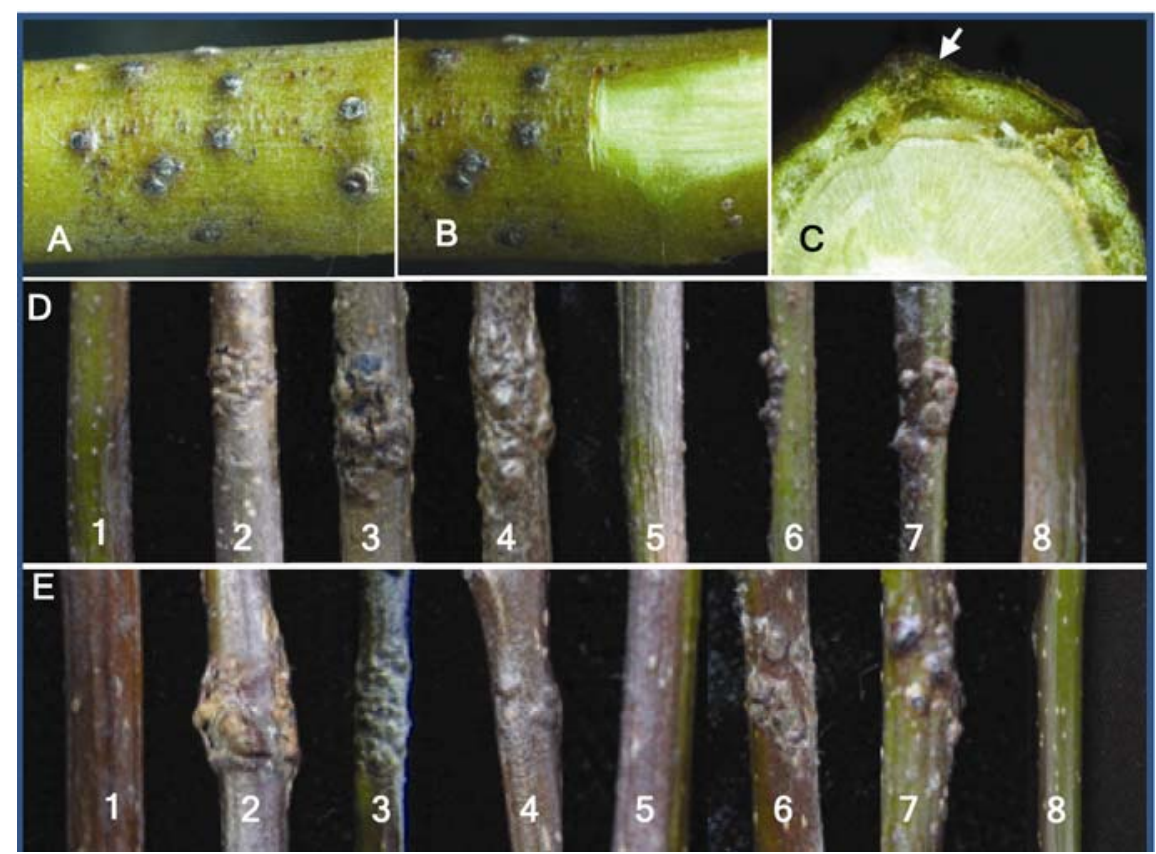

Fig. 4. Symptoms on unwounded apple and pear shoots 50 days after inoculation (via mycelium plugs) with different isolates of Botryosphaeria dothidea and related species A, Warts on shoot. B and C, Longitudinal and cross section through wart showing healthy cortex. Wart symptom on apple (D) and pear (E) induced by different isolates. 1, Control. 2, LW018. 3, LXS130103. 4, Bd1864. 5, CBS115476. 6, LXS030301. 7, LXS170101. 8, CBS118822.

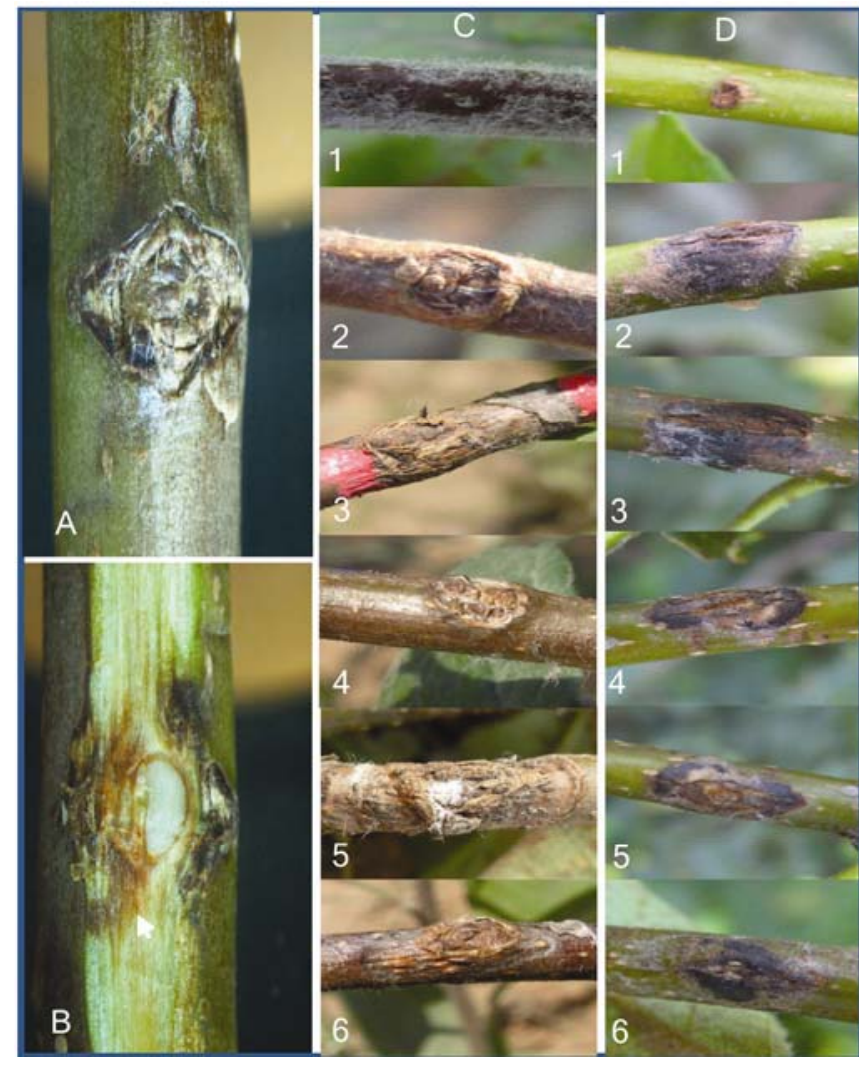

Fig. 5. Symptoms on wounded apple and pear shoots 20 days after inoculation (via mycelium plugs) with different isolates of Botryosphaeria dothidea and related species. A, Canker on shoot. B, Longitudinal section through canker showing discoloration or collapse of cortex tissue (arrows indicated the discoloration areas). C, Apple shoots. D, Pear shoot. 1, Control. 2, LXS130103. 3, 3K. 4, CBS115476. 5, CBS118822. 6, Bd1864

should be reviewed and the name of the disease should be revised to avoid the confusion.

In this study, B. dothidea from poplar caused rot of apple and pear fruit and canker but not warts on apple and pear shoots. These findings suggest that $B$. dothidea from deciduous trees can serve as inoculum for Botryosphaeria disease of apple. B. dothidea has been reported to infect a wide range of hosts, including apple (5), peach (5), kiwifruit (22), pear (21), olive (19), and pistachio $(20,31)$. None of the isolates from hosts other than pear and apple in the current study caused warts on apple or pear. Researchers previously reported that $B$. dothidea pathogenicity differs for isolates from peach versus apple $(18,24)$. Therefore, variation in pathogenicity among isolates of $B$. dothidea from different hosts may exist, but its mechanism remains to be investigated.

Our results showed that $B$. dothidea can induce warts or lesions with necrotic tissue on apple and pear branches depending on the conditions. Lesions usually formed when the branches were wounded in the current study, but lesions were also observed on 30 to $60 \%$ of unwounded inoculation sites on nursery plants subjected to drought but not on plants that were regularly irrigated (unpublished data). In the apple orchards in China, twig dieback caused by Botryosphaeria is often observed in spring, when drought is common in most apple growing areas. During this study, we observed cankers caused by Botryosphaeria on the trunks of young apple trees that died from drought in spring but that appeared healthy in the previous autumn before planting (unpublished observations). In the United States, the occurrence of Botryosphaeria canker on apple has also been related to drought (5).

In contrast to lesions, warts formed only on unwounded shoots, and wart formation was closely related to the growth of the host. Wart formation was observed 1 to 2 months after inoculation only if the inoculation was carried out between May and July, when shoots were rapidly growing. When shoots were inoculated later than July, warts usually did not form until the next summer (unpublished data). The formation of warts may be a resistance response of the host to infection by $B$. dothidea. However, our study could not explain why the wart symptom on branches is common in East Asian countries but is uncommon in other regions, such as the southeastern United States, where Fuji is grown. In our inoculation experiments, four isolates from the United States (Bd1, $\mathrm{Bd} 1862$, Bd1864, and Bd1881) caused warts on apple similar to those caused by isolates from China. Perhaps environmental factors favor wart production in the Far East.

Results of this study also showed that variation in pathogenicity was found among isolates of $B$. dothidea. A previous study showed 

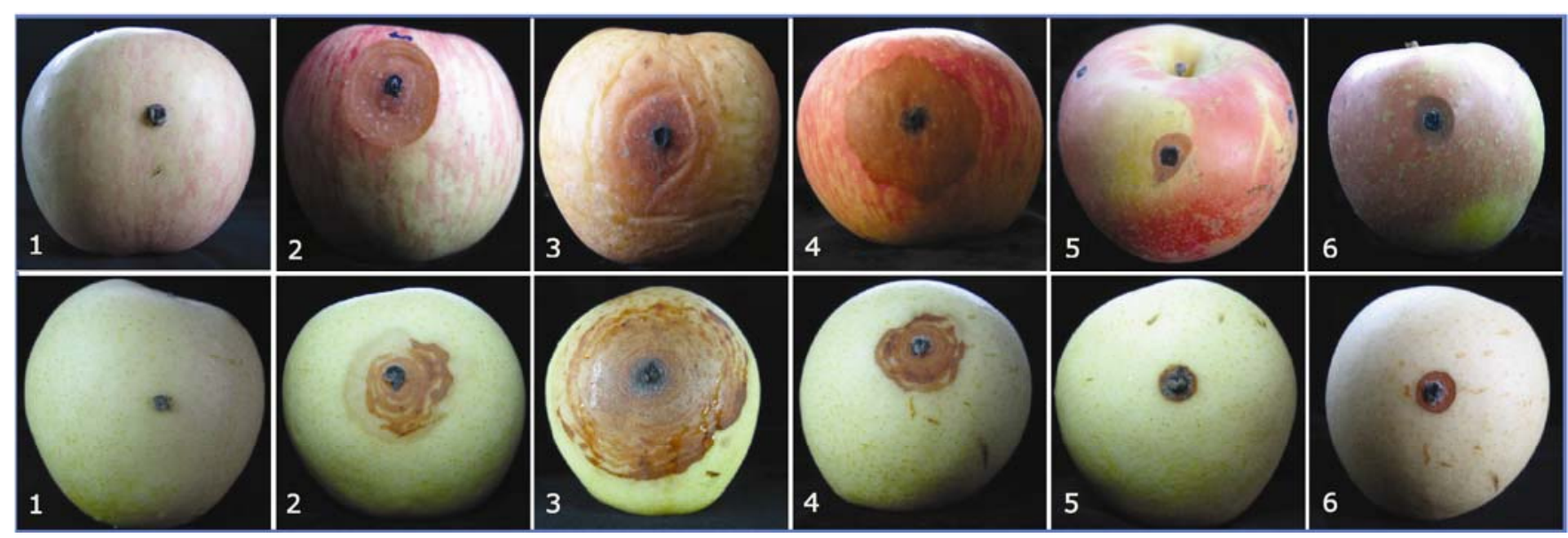

Fig. 6. Symptoms on unwounded apple (top row) and pear (bottom row) fruit 10 days after inoculation (via mycelium plugs) with different isolates of Botryosphaeria dothidea. 1, Control. 2, LW018. 3, CBS118822 (lesion has expanded to the entire fruit). 4, Bd1864. 5, CBS115476. 6, 3K.

that resistance of apple trees to $B$. dothidea was affected by cultivar, temperature, rain fall, isolates used, and inoculation method and position (26). A recent study also found that the virulence of isolates of $B$. dothidea and B. obtusa varied depending on the assay used (6).

During our 2-year investigation, $B$. dothidea was the only species of Botryosphaeria isolated from apple in China. B. obtusa, which is common on apple in Japan and the United States $(5,21)$, was not found in this study. Our results also suggest that the anamorph of the apple ring rot pathogen should belong to Fusicoccum, not Dothiorella. The anamorph of Botryosphaeria has been classified into two groups based on the shape and the color of the conidia: a Fusicoccum group with hyaline conidia and a Diplodia group with dark conidia (11). The shape and the size of conidia of the apple ring rot pathogen reported here were consistent with that reported for $F$. aesculi (9). The Neofusicoccum anamorph of Neofusicoccum ribis $(=B$. ribis) can be distinguished from $B$. dothidea by the size of conidia (15).

To our knowledge, this study is the first to combine morphological data, sequences of multiple genes, and pathogenicity tests in order to clarify the confusion regarding the pathogen of apple ring rot in Asia. Our results indicated that apple ring rot and white rot are the same disease. Consequently, management strategies developed in one region of the world should also be effective in others.

\section{Acknowledgments}

This study was supported by the Special Fund for Agro-scientific Research in the Public Interest (3-22) under the Chinese Ministry of Agriculture, the Earmarked Fund for Modern Agro-industry Technology Research System (nycytx08-04-02), and the Special Fund from the Chinese Ministry of Education (PCSIRT-IRT1042). We thank Drs. T. B. Sutton of North Carolina State University, USA; J. Y. Uhm of Kyungpook National University, Korea; Hideo Ishii of Japanese National Institute for Agro-Environmental Sciences; and B. H. Li of Qing Dao Agricultural University for providing isolates of B. dothidea. We also thank Drs. T. B. Sutton of North Carolina State University and C. L. Xiao of Washington State University for reviewing the manuscript before submission and Bruce Jaffee for editing the manuscript.

\section{Literature Cited}

1. Anonymous. 1959. List of pathogens and insets on fruit trees in China. 1st ed. China Agriculture Press.

2. Anonymous. 1994. List of pathogens and insets on fruit trees in China. 2nd ed. China Agriculture Press.

3. Anonymous. Botryosphaeria berengeriana $\mathrm{f}$. sp. piricola. Data sheets on quarantine pests. Prepared by CABI and EPPO for the EU under contract 90/399003.

4. Biggs, A. R., and Miller, S. S. 2003. Relative susceptibility of selected apple cultivars to Botryosphaeria dothidea. HortScience 38:400-403.

5. Brown, E. A., and Britton, K. O. 1986. Botryosphaeria diseases of apple and peach in the southeastern United States. Plant Dis. 70:484.

6. Brown-Rytlewski, D. E., and McManus, P. S. 2000. Virulence of Botryosphaeria dothidea and Botryosphaeria obtusa on apple and management of stem cankers with fungicides. Plant Dis. 84:1031-1037.

7. Chen, C. 1999. Advances in the research of apple ring rot. Acta Phytopa- thol. Sin. 29:1-7 (in Chinese)

8. Chen, H. Y., Tian, C. M., Liang, J., and Zhang, X. Y. 2006. Studies on taxonomy of pathogenic fungal of Botryosphaeria and its anamorphs causing tree canker. J. Northwest Forestry Univ. 21:145-150 (in Chinese).

9. Crous, P. W., and Palm, M. E. 1999. Reassessment of the anamorph genera Botryodiplodia, Dothiorella and Fusicoccum. Sydowia 52:167-175.

10. Crous, P. W., Slippers, B., Wingfield, M. J., Rheeder, J., Marasas, W. F. O., Phillips, A., Alves, A., Burgess, T. I., Barber, P. A., and Groenewald, J. Z. 2006. Resolving phylogenetic lineages in the Botryosphaeriaceae. Stud. Mycol. 55: 235-253.

11. Denman, S., Crous, P. W., Taylor, J. E., Kang, J. C., Pascoe, I., and Wingfield, M. J. 2000. An overview of the taxonomic history of Botryosphaeria, a re-evaluation of its anamorphs based on morphology and ITS rDNA phylogeny. Stud. Mycol. 45:129-140.

12. Glass, N. L., and Donaldson, G. C. 1995. Development of primer sets designed for use with the PCR to amplify conserved genes from filamentous ascomycetes. Appl. Environ. Microbiol. 61:1323-1330.

13. Guo, L. Y., Li, J. Y., Li, B. H., Zhang, X. Z., Zhou, Z. Q., Li, G. X., Wang, Y. Z., Li, X. J., Huang, L. L., Sun, G. Y., and Wen, Y. D. 2009. Investigation on the occurrence and chemical control of Botryosphaeria canker of apple in China. Plant Prot. 35:120-123 (in Chinese).

14. Hall, T. A. 1999. BioEdit: A user-friendly biological sequence alignment editor and analysis program for Windows 95/98/NT. Nucleic Acids Sympos. Ser. 41:95-98.

15. Jacobs, K. A., and Rehner, S. A. 1998. Comparison of cultural and morphological characters and ITS sequences in anamorphs of Botryosphaeria and related taxa. Mycologia 90:601-610.

16. Jones, A. L., and Aldwinckle, H. S. 1990. Compendium of Apple and Pear Disease. American Phytopathological Society, St. Paul, MN.

17. Kim, K. W., Kim, K. R., and Park, E. W. 2005. An infection model of apple white rot based on conidial germination and appressorium formation of Botryosphaeria dothidea. Plant Pathol. J. 21:322-327.

18. Koganezawa, H., and Sakuma, T. 1984. Causal fungi of apple fruit rot. Bull. Fruit Tree Res. Stn. Jpn. Ser. C 11:49-62.

19. Lazzizera, C., Frisullo, S., Alves, A., and Phillips, A. J. L. 2008. Morphology, phylogeny and pathogenicity of Botryosphaeria and Neofusicoccum species associated with drupe rot of olives in southern Italy. Plant Pathol 57:948-956.

20. Ma, Z. H., and Michailides, T. J. 2002. Characterization of Botryosphaeria dothidea isolates collected from pistachio and other plant hosts in California. Phytopathology 92:519-526.

21. Ogata, T., Sano, T., and Harada, Y. 2000. Botryosphaeria spp. isolated from apple and several deciduous fruit trees are divided into three groups based on the production of warts on twigs, size of conidia, and nucleotide sequences of nuclear ribosomal DNA ITS regions. Mycoscience 41:331-337.

22. Pennycook, S. R., and Samuels, G. J. 1985. Botryosphaeria and Fusicoccum species associated with ripe fruit rot of Actinidia deliciosa (kiwifruit) in New Zealand. Mycotaxon 24:445-458.

23. Phillips, A. J. L., Alves, A., Pennycook, S. R., Johnston, P. R., Ramaley, A., Akulov, A., and Crous, P. W. 2008. Resolving the phylogenetic and taxonomic status of dark-spored teleomorph genera in the Botryosphaeriaceae. Persoonia 21:29-55.

24. Pusey, P. L. 1993. Role of Botryosphaeria species in peach tree gummosis on the basis of differential isolation from outer and inner bark. Plant Dis 77:170-174.

25. Salemi, M., and Vandamme, A. M. 2003. The Phylogenetic Handbook: A Practical Approach to DNA and Protein Phylogeny. Cambridge University Press.

26. Savocchia, S., Steel, C. C., Stodart, B. J., and Somers, A. 2007. Pathogenic- 
ity of Botryosphaeria species isolated from declining grapevines in sub tropical regions of Eastern Australia. Vitis 46:27-32.

27. Slippers, B., Crous, P. W., Denman, S., Coutinho, T. A., Wingfield, B. D., and Wingfield, M. J. 2004. Combined multiple gene genealogies and phenotypic characters differentiate several species previously identified as Botryosphaeria dothidea. Mycologia 96:83-101.

28. Slippers, B., Fourie, G., Crous, P. W., Coutinho, T. A., Wingfield, B. D., and Wingfield, M. J. 2004. Multiple gene sequences delimit Botryosphaeria australis sp. nov. from B. lutea. Mycologia 96:1030-1041.

29. Slippers, B., Smit, W. A., Crous, P. W., Coutinho, T. A., Wingfield, B. D., and Wingfield, M. J. 2007. Taxonomy, phylogeny and identification of Botryosphaeriaceae associated with pome and stone fruit trees in South Africa and other regions of the world. Plant Pathol. 56:128-139.

30. Slippers, B., and Wingfield, M. J. 2007. Botryosphaeriaceae as endophytes and latent pathogens of woody plants: Diversity, ecology and impact. Fungal Biol. Rev. 21:90-106.

31. Smith, D. R., Michailides, T. J., and Stanosz, G. R. 2001. Differentiation of a Fusicoccum sp. causing panicle and shoot blight on California pistachio trees from Botryosphaeria dothidea. Plant Dis. 85:1235-1240.

32. Smith, D. R., and Stanosz, G. R. 2001. Molecular and morphological differ- entiation of Botryosphaeria dothidea (anamorph Fusicoccum aesculi) from some other fungi with Fusicoccum anamorphs. Mycologia 93:505-515.

33. Tamura, K., Dudley, J., Nei, M., and Kumar, S. 2007. MEGA4: Molecular evolutionary genetics analysis (MEGA) software version 4.0. Mol. Biol. Evol. 24:1596-1599.

34. White, T. J., and Bruns, T. 1990. Amplification and direct sequencing of fungal ribosomal RNA genes for phylogenetics. Page 315-322 in: PCR Protocols: A Guide to Methods and Applications. M. A. Innis, D. H. Gelfand, J. J. Sninsky, and T. J. White, eds. Academic Press, New York.

35. Xiang, W. N. 1957. Reference of Mycology and Plant Pathology in China. Science Press, Beijing.

36. Zhou, S., Smith, D. R., and Stanosz, G. R. 2001. Differentiation of Botryosphaeria species and related anamorphic fungi using inter simple or short sequence repeat (ISSR) fingerprinting. Mycol. Res. 105:919-926.

37. Zhou, S., and Stanosz, G. R. 2001. Relationships among Botryosphaeria species and associated anamorphic fungi inferred from the analyses of ITS and 5.8S rDNA sequences. Mycologia 93:516-527.

38. Zhou, S., and Stanosz, G. R. 2001. Primers for amplification of mt SSU rDNA, and a phylogenetic study of Botryosphaeria and associated anamorphic fungi. Mycol. Res. 105:1033-1044. 